\title{
Relationship between emotionality of intruders and aggressive behavior of residents in rats
}

\author{
YASUMASA ANNEN and OSAMU FUJITA \\ Institute of Psychology, University of Tsukuba, Niihari, Ibaraki 305
}

\begin{abstract}
Isolated inbred strains of rats selected for high and low levels of emotionality were tested for their aggression provoking tendency when they were used as intruders and introduced individually into the established colonies $(n=4)$ composed of one female and four male Wistar rats. Several social behaviors were quantified for $450 \mathrm{~s}$ by VTR observation. It was indicated that the low emotional intruders $(n=8)$ elicited from male residents significantly more biting, lateral display, on-top-of and chasing than the high emotional intruders $(n=7)$. It was suggested that these differences were related with the difference of the activeness of defense behavior inherent in the two strains. Discussion was made with reference to social cognition developed through their interaction between residents and intruder.
\end{abstract}

Key words: emotionality, aggression, social cognition, colony-intruder model, selective breeding, isolation.

Domesticated has been said to display relatively little spontaneous aggressive behavior since it was convinced that domesticated strains of rats retained only vestigial remnants of attack and defense patterns of their ancestors (Lockard, 1968) and were lacking in a variety of aggressive behaviors displayed by wild rats (Barnett, 1960, 1963). However, recent studies have made clear that dominant males of domesticated rat collonies attacked and sometimes killed unfamiliar male rats introduced into their colonies (Blanchard, Blanchard, Takahashi, \& Kelley, 1977; Blanchard, Fukunaga, Blanchard, \& Kelley, 1975; Luciano \& Lore, 1975).

There are a number of studies indicating that aggression of resident rats are elicited in those social contexts by nonbehavioral stimuli emanating from strange intruders, or odors cues. For example, peripheral anosmia induced by intranasal application of a zinc sulfate solution abolished resident's aggression toward an intruder (Albert \& Galef, 1971; Flannelly \& Thor, 1976). Anethetized intruders were attacked by feral (Albert \& Galef, 1973) and domesticated rats (Blanchard et al., 1975).

On the other hand, it was also indicated that behavioral stimuli had the prop- erty of eliciting aggression. For example, Blanchard and Blanchard (1977) described the aggressive interactions of rats in the social situation. If a strange male rat is introduced in the colony, then the dominant male will approach the intruder and show a number of investigatory behaviors, including sniffing, which are quickly followed by piloerection, unless the introduced animal was a colony member. After piloerection, biting, chasing, lateral display, and on-top (full aggressive posture) followed. After these furious attacks lasting for about 5-6 min, the intruder becomes almost always motionless, either lying on the back, boxing, or freezing in a crouching position. The dominant male's attacks on the intruder then ceases. But if the intruder should move suddenly, the dominant male usually resumes the attack (Blanchard \& Blanchard, 1977).

Then, it is conceivable that the intruder's behavior patterns may differentially affect the social cognition of the dominant male of the colony and also affect its aggressive behavior. However, there are few studies which systematically investigated possible relationship between intruder's behavioral characteristics and aggression elicited 
among resident rats. In the present experiment, two strains of rats, genetically known to be different in several aspects of their behavior, were used as intruders and their aggression-eliciting tendency in colony resident rats was examined.

For the past 12 years, Fujita and his co-workers have been bidirectionally selecting rats to establish different levels of emotionality: Tsukuba high (THE) and low (TLE) emotional strains of rats (Fujita, Abe, \& Nakamura, 1976). These strains differ in aggressiveness and in behavior in a novel place. The THE rats were found to be less aggressive in an isolated situation (Annen \& Fujita, 1984), and to freeze in response to novel stimuli or in a novel place (Fujita, Nakamura, Miyamoto, Katayama, Kamazuka, \& Katoh, 1980). In contrast, the TLE rats were found to be more aggressive than the THE and to explore more actively in a novel situation. Moreover, the TLE would struggle and gnaw the wire-mesh to escape from the underwater confinement, while the THE remained immobile in the underwater confinement. ${ }^{1}$

These behavioral strain differences are assumed to differentially affect the behavior of the colony residents. The present experiment was conducted to examine this possibility.

\section{Methods}

\section{Subjects}

Intruders. Seven male inbred rats of the Tsukuba high emotional (THE) strain and eight male inbred rats of the Tsukuba low emotional (TLE) strain were used for the intruders. The origin and history of these strains are described in Fujita (1975) and Fujita et al. (1976). Briefly, these

\footnotetext{
1 Fujita, O. Behavioral differences in Tsukuba emotional strains of rat: 50 -Coping behavior in underwater confinement. Paper presented at the 48th Annual Convention of the Japanese Psychological Association, Osaka, October, 1984.
}

two strains were selectively bred according to the amount of ambulation in the brightly lighted runway situation. The mean $(S D)$ ambulation and defecation scores in the runway test measured at 60 days old were $0.29(0.70)$ and 2.57 (1.19) for THE rats and $74.63(35.75)$ and 0.63 (1.11) for TLE rats, respectively. There was no overlap in the distribution of ambulation between the two strains.

Colony-residents. Four colonies of WistarImamichi rats were prepared in order to test aggression elicited in the colony residents upon the introduction of the intruder. Each colony was composed of four males and a female.

Another 25 Wistar-Imamichi male rats were reared in isolation and used as intruders only for the purpose of increasing the likelihood of aggression occurrence among the residents during the later tests with THE and TLE.

\section{Apparatus}

Resident rats were reared in four plywood pens ( 60 by 88 by $60 \mathrm{~cm}$ ). The floor of the pen was covered by wood shaving. Movable VTR equipment was arranged to monitor the whole floor of a pen under two 60-W red lamps during the dark period. A stainless steel cage (21 by 15 by $15 \mathrm{~cm}$ ) was used for isolation rearing.

\section{Procedure}

Prior to the intruder tests of THE and TLE strains, four female and 16 male Wistar rats were formed into four colonies at about two months of age and were reared in groups of five rats for more than two months. During this period, isolation-reared Wistar male rats were individually introduced into each colony once a week for approximately $10 \mathrm{~min}$ at a time. At the begining of this experiment, the age of those Wistar intruders ranged from 56 to 64 days. Pups born in the colony were removed from the colony when they were at 21 days of age. 
Intruders of both the THE and TLE strains were reared until approximately 90 days old in ordinary breeding cages, each containing four males of the same strain, and were then shifted to the individual rearing for another 90 days. This was done with the assumption that isolationreared rats, when used as intruders, would elicit more aggression from residents.

Intruders were individually introduced into one of the four colonies for $450 \mathrm{~s}$ in a random order, each intruder rat being used only once. Each colony had the intruder test once or two times a day with the interval of about one hour for two days. These tests were conducted under dim red lighting during the dark period of a day without removing pups, if any.

Occurrence (1) or nonoccurrence (0) of the following behaviors of each resident toward an intruder was counted in 10-s interval by VTR observation: biting, lunging, lateral display, on-top-of, chasing, and aggressive grooming. The selection of these behavior patterns were based on our previous observation (Annen \& Fujita, 1984). The sum of the above six scores was referred to as the total aggression score. The time, measuring from the introduction of an intruder to a colony, that a resident bit the intruder for the first time was referred to as a latency to bite (max. $=$ $450 \mathrm{~s})$. Intruder's scores of boxing and freezing were also recorded. Maximum score was 45 for each behavior of a resident. Scores of four male residents were summed up within each measurement.

Following the intruder test, the intruder was removed from the colony and the number of wounds on its dorsal and ventral side of the body was counted, with the length of wound not taking into account.

\section{Results}

Mean total aggression score of male residents against the THE (left) and the TLE (right) intruders are shown in Fig.

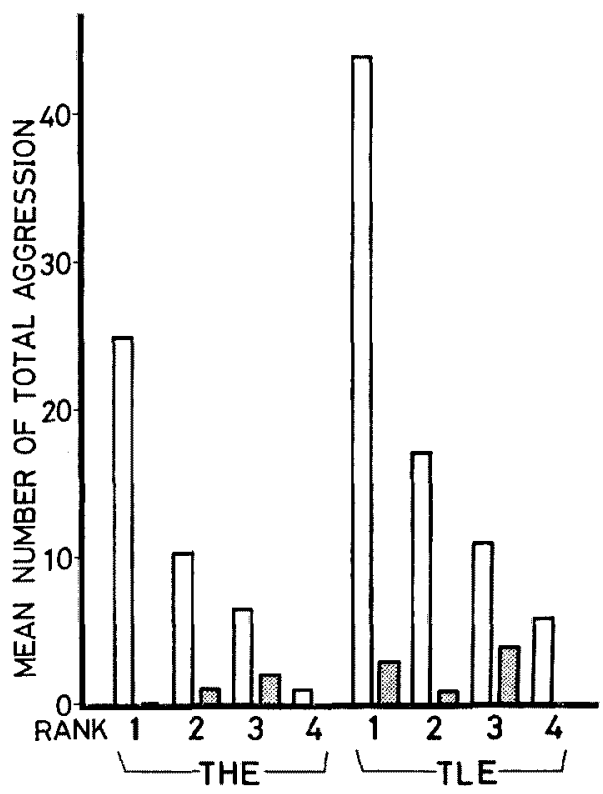

Fig. 1. Mean total aggression scores shown by male residents against the THE (left) and the TLE (right) intruders (white bars) and against the rest of male residents of the colonies (shaded bars).

1. For each colony, four males were rank ordered in the number of total aggression and the mean number of total aggression across colonies was obtained from the rats having the same rank and the results are shown by white bars of Fig. 1. Corresponding mean total aggression against the rest of the male residents are shown by the shaded bars. Figure 1 clearly indicates that more aggression was elicited by the TLE intruders than by the THE. It is also clear from Fig. I that one male resident of each colony attacked an intruder chiefly and its total aggression score accounted for $57.6 \%$ of that of all four male residents of the colony. However, such a male was not necessarily a dominant male of the colony. In one of four colonies, the most intruder-attacker was attacked by less intruder-attackers.

More detailed results of intruder test are shown in Table 1 for each behavioral score separately. Transitions of several aggressive behaviors over 15 blocks of 
Table 1

Summary of the results of intruder test for each behavior score as well as of ANOVA

\begin{tabular}{|c|c|c|c|c|c|c|c|}
\hline \multirow[b]{3}{*}{ Behavior Items } & \multicolumn{4}{|c|}{ Strain } & \multirow{2}{*}{\multicolumn{3}{|c|}{$F$ value }} \\
\hline & \multicolumn{2}{|c|}{$\mathrm{THE}(n=7)$} & \multicolumn{2}{|c|}{ TLE $(n=8)$} & & & \\
\hline & Mean & $S D$ & Mean & $S D$ & $\begin{array}{l}\text { Strain } \\
(d f: 1 / 13\end{array}$ & $\begin{array}{l}\text { Block } \\
14 / 182\end{array}$ & $\begin{array}{l}\text { St } \times \text { Bl } \\
14 / 182)\end{array}$ \\
\hline \multicolumn{8}{|c|}{ Male residents' aggression against intruders } \\
\hline Biting & 9.14 & $(4.52)$ & 17.63 & $(7.07)$ & $6.09 *$ & $3.54 * *$ & 0.95 \\
\hline Lunging & 0.57 & $(1.40)$ & 1.13 & $(1.17)$ & 0.96 & 0.89 & 1.09 \\
\hline Lateral Display & 0.71 & $(0.70)$ & 3.88 & $(1.76)$ & $19.51 * *$ & $2.47 * *$ & $1.86^{*}$ \\
\hline On-top-of & 9.43 & $(10.03)$ & 21.75 & $(12.16)$ & $5.26 *$ & $1.83 *$ & 1.10 \\
\hline Chasing & 1.00 & $(1.07)$ & 4.63 & $(3.12)$ & $7.43 *$ & 1.40 & 1.17 \\
\hline Aggressive Grooming & 24.00 & $(8.41)$ & 29.38 & $(9.08)$ & 1.30 & $5.79 * *$ & 0.98 \\
\hline Total Aggression & 44.86 & $(22.27)$ & 78.38 & $(30.19)$ & $5.65^{*}$ & $4.20 * *$ & 0.92 \\
\hline Latency to bite $(s)$ & 45.00 & $(11.58)$ & 21.88 & $(10.20)$ & $t=3.83^{* *}$ & $(d f=$ & 13) \\
\hline \multicolumn{8}{|c|}{ Female resident's aggression against intruders } \\
\hline Biting & 0.29 & $(0.70)$ & 2.50 & $(2.92)$ & 3.35 & 1.08 & 1.04 \\
\hline Total Aggression & 5.43 & $(5.34)$ & 13.25 & $(10.64)$ & 1.16 & 0.96 & 0.95 \\
\hline \multicolumn{8}{|l|}{ Intruders } \\
\hline Boxing & 0.43 & $(0.49)$ & 6.38 & $(3.53)$ & $19.30 * *$ & 0.78 & 0.66 \\
\hline Freezing & 37.00 & $(5.13)$ & 22.00 & $(5.87)$ & $23.20 * *$ & $4.80 * *$ & 1.28 \\
\hline Number of Dorsal Wound & 5.43 & $(2.82)$ & 10.25 & $(4.38)$ & $t=2.32 *$ & \multicolumn{2}{|c|}{$(d f=13)$} \\
\hline Number of Ventral Wound & 0.71 & $(0.70)$ & 1.13 & $(1.05)$ & $t=0.84$ & \multicolumn{2}{|c|}{$(d f=13)$} \\
\hline
\end{tabular}

$30 \mathrm{~s}$ are shown in Fig. 2. Two-factor (strain $\times$ block) analysis of variance was performed for Fig. 2 upon each measure. It was indicated that the TLE intruders elicited from male residents significantly more biting $(F=6.09, d f=1 / 13, p<.05)$, lateral display $(F=19.51, d f=1 / 13, p<$ $.01)$, on-top-of $(F=5.26, d f=1 / 13, p<.05)$,

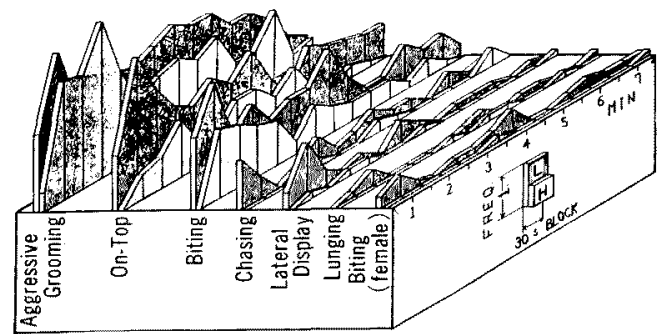

Fig. 2. Transitions of various aggressive behaviors over 15 blocks of 30 s elicited by the THE intruders (right side of each pair of the walls) and by the TLE intruders (left side). chasing $(F=7.43, d f=1 / 13, p<.05)$ and total aggression $(F=5.65, d f=1 / 13, p<.05)$ than the THE intruders. Such differences were also reflected in the actual difference of the number of wounds in dorsal side of the THE and TLE intruders $(t=2.32, d f=13, p<.05)$. The TLE was bitten by male resident with shorter latency $(t=3.83, d f=13, p<.01)$ than the THE. The TLE had also shorter latency to the peak time than the THE to receive aggressive grooming, on-top-of, chasing, and lateral display from male residents (Fig. 2), but there was a significant strain by block interaction only in lateral display $(F=$ $1.86, d f=14 / 182, p<.05)$. There was no significant difference between any of the aggressive behaviors of female resident shown to the two strains.

As to the defensive behavior of the intruders, the THE took less active strategy such as freezing $(F=23.20, d f=1 / 13, p<$ 
$.01)$, while the TLE took more active one such as boxing $(F=19.30, d f=1 / 13, p<.01)$ and flight whose difference was reflected in the difference of chasing on the side of the residents.

\section{Discussion}

The results clearly indicated that the TLE intruders had greater inclination than the THE to provoke aggression in residents. This finding may be related to the findings of Luciano and Lore (1975) and Brain, Benton, Howell, and Jones (1980) which showed that active intruders elicited more aggression from residents.

The resident rats, especially the dominant one, of a colony are assumed to store the information about the odors and the behavior traits of other residents and continually compare this information with the situation they are facing with. Since the TLE intruders explored the floor of the colony as soon as they were introduced into it, the TLE intruders were easily detected and attacked rapidly by residents, while the THE intruders were relatively motionless and to that extent their detection was delayed. The difference of intruders' emotionality in response to the resident's first attack was also reflected in the difference in chasing scores of male residents. The greater tendency of the TLE rats to explore and to flee from the attacker provoked further aggression. Such active defense behavior of the TLE intruders thus forms a discrepancy with the stored information of the residents. This then suggests that the aggression of residents may be elicited by behavioral stimuli.

Such active defensiveness of the TLE may be related to its high aggressiveness (Annen \& Fujita, 1984) and active coping behavior in the uncontrollable situation of underwater confinement. These behavioral differences inherent in the two strains affected social interaction. Then, it is suggested that emotionality of in- truder may play an important role in the social interaction of rats through its overt defensive behavior.

\section{References}

Albert, J. R., \& Galef, B. G., Jr. 1971 Acutc anosmia in the rat: A behavioral test of a peripherally induced olfactory deficit. Physiology and Behavior, 6, 619-621.

Albert, J. R., \& Galef, B. G., Jr. 1973 Olfactory cues and movement: Stimuli mediating intraspecific aggression in the wild Norway rat. Journal of Comparative and Physiological Psychology, 85, 233-242.

Annen, Y., \& Fujita, O. 1984 Intermale aggression in the rat selected for emotional reactivity and their reciprocal $F 1$ and F2 hybrids. Aggressive Behavior, 10, 11-19.

Barnett, S. A. 1960 Social behavior among tame rats and among wild-white hybrids. Proceedings of the Zoological Society of London, 134, 611-621.

Barnett, S. A. 1963 The rat: A study in behavior. Chicago: Aldine.

Blanchard, R. J., \& Blanchard, D. C. 1977 Aggressive behavior in the rat. Behavioral Biology, 21, 197-224.

Blanchard, R. J., Blanchard, D. C., Takahashi, T., \& Kelley, M. 1977 Attack and defensive behavior in the albino rat. Animal Behaviour, 25, 622-634.

Blanchard, R.J., Fukunaga, K. K., Blanchard, D. C., \& Kelley, M. 1975 Conspecific aggression in the laboratory rat. Journal of Comparative and Physiological Psychology, 89, 1204-1209.

Brain, P. F., Benton, D., Howell, P. A., \& Jones, S. E. 1980 Resident rats' aggression toward intruders. Animal Learning and Behavior, 8, 331-335.

Flannelly, K.J., \& Thor, D. H. 1976 Territorial behavior of laboratory rats under conditions of peripheral anosmia. Animal Learning and Behavior, 4, 337-340.

Fujita, O. 1975 Behavior-genetic analysis of responses in runway test as measures of emotional reactivity in rats. I. Phenotypic variations and heritability estimates based on offspring-parents regressions. Japanese Journal of Psychology, 66, 281-292. (In Japanese with English summary)

Fujita, O., Abe, I., \& Nakamura, N. 1976 Selection for high and low emotional reactivity based on the runway test in the rat: The first seven 
generations of selection. Hiroshima Forum for Psychology, 3, 57-62.

Fujita, O., Nakamura, N., Miyamoto, K., Katayama, T., Kamazuka, M., \& Katoh, H. 1980 Behavioral differences in the rat selected for high and low emotional reactivity. Tsukuba Psychological Research, 2, 19-31. (In Japanese with English summary)
Lockard, R. B. 1968 The alino rat: A defensible choice or a bad habit? American Psychologist, 23, 734-741.

Luciano, D., \& Lore, R. 1975 Aggression and social experience in domesticated rats. Journal of Comparative and Physiological Psychology, 88, 917-923.

(Received April 27, 1984; accepted March 9, 1985) 